Medicine in the elderly

\title{
Breast cancer in the elderly
}

\author{
M Bellet, C Alonso, B Ojeda
}

\begin{abstract}
Summary
Breast cancer in the elderly has attracted considerable interest in recent years for three main reasons. Firstly, information concerning the profile (clinical and biological) of the disease in the geriatric population is scarce; secondly, the number of patients is increasing, and thirdly there are conflicting data regarding the actual effectiveness of the different treatments. The present review attempts to outline the specific characteristics of this malignancy in the elderly in terms of histological pattern, stage at diagnosis, and outcome. The feasibility of standard therapies (mastectomy/lumpectomy, axillary clearance, and radiotherapy) in the elderly is carefully analysed, and compared to the efficacy of less aggressive procedures. The use of tamoxifen as a primary treatment, instead of surgery, is critically reconsidered, as well as its use as an adjuvant therapy. Finally, the effectiveness of systemic therapy in advanced disease is also discussed.
\end{abstract}

Keywords: elderly, breast cancer, management

Determinants of care
applied to elderly breast
cancer patients
- functional disability
- concomitant diseases
- scanty socioeconomical resources
- distance to radiotherapeutic centre
- difficulties regarding access to
transport
- poor compliance

Box 1

Department of Medical Oncology, Hospital Sta Creu i Sant Pau, Avda S Antoni Ma Claret 167, 08025 Barcelona, Spain

M Bellet

C Alonso

B Ojeda

Accepted 1 June 1995
Breast cancer continues to be the most common neoplasm and is the second leading cause of malignant deaths in women. ${ }^{1}$ According to statistics from western countries, breast cancer incidence substantially increases with age, at least until 85 years. ${ }^{2}$ In recent years, the average age of women with newly diagnosed breast cancer has risen notably (from 55.5 to 62.5 ). ${ }^{3}$ As the elderly population increases compared to that of younger adults there is also a dramatic increase in the absolute number of new elderly breast cancer patients. ${ }^{4,5}$ Furthermore, for a variety of reasons (box 1 ) this group of elderly patients may not benefit from the therapeutic advances made in breast cancer. ${ }^{6-9}$

Comorbidity precludes standard therapy being given in many cases: ${ }^{6}$ the proportion of women with two or more diseases is $45 \%, 61 \%$ and $70 \%$ for women of $60-69,70-79$, and $\geqslant 80$ years old, respectively. ${ }^{10}$ The percentage of people requiring assistance in daily living activities ranges from $6-8 \%$ among those aged $65-74$, to $25 \%$ among those over 85 years. ${ }^{11,12}$

In other cases, age per se constitutes the only determinant of this 'suboptimal care'. Greenfield $e t a l^{6}$ found that age was an independent risk factor for not receiving definitive treatment even in patients without comorbidity and with early disease. This finding has been corroborated by other studies ${ }^{7-9}$ and probably results from misjudging the life expectancy of the elderly woman (see box 2). ${ }^{13}$ For these same reasons, older patients have systematically been excluded from most clinical trials. The result is an alarming lack of specific data concerning this subset of patients.

\section{Profile of breast cancer in the elderly}

Does breast cancer in the elderly have specific biohistological characteristics? Tumours in postmenopausal women, compared with those in premenopausal women show a lower proliferative index, measured by $\left[{ }^{3} \mathrm{H}\right]$ thymidine labelling index ${ }^{14}$ and S-phase fraction, a higher incidence of oestrogen receptor, and a higher degree of differentiation. ${ }^{15-17}$ Valentini et al, ${ }^{18}$ in a study of the breast cancer samples from 476 patients over 70, confirmed a high number of oestrogen and progesterone-receptor positivities $(83 \%$ and $61 \%$, respectively) for the tumours in this specific age-group. The authors also reported a notorious proportion of aneuploid tumours ( $74 \%$, median DNA index: $3.7 \%$ ) and a mild to moderate proliferative activity (median $\left[{ }^{3} \mathrm{H}\right]$ thymidine labelling index: $3.4 \%$ ).

Are the elderly diagnosed in more advanced stages? Is the nodal involvement similar to that found in younger patients?

We analysed the data of several retrospective series and statistical sources. ${ }^{2,8,19-30}$ The results of this review can be summarised as follows:

- The most frequent stage for all age groups is II. ${ }^{23}$

- Among women over 75 years of age, a greater number of stage III, IV and unknown stages are registered. ${ }^{2,23}$ The proportion of unknown stages ranges from $9.2 \%{ }^{26}$ to $21 \% .^{21}$

- Early studies ${ }^{20,21}$ suggested that a 'nonnodal variant' could be common among the elderly. More recently, Gazetas et $a l^{26}$ describe $37 \%$ positive nodes among the elderly, which is only somewhat lower than the general $40-50 \%$ found among patients of all ages. However, due to the low number of nodal clearances carried out in aging patients in most reports, no definitive conclusions can be reached.

If elderly patients are more likely not to receive standard therapy, what treatment is usually administered?

Mastectomy (simple, total or radical) has been the most widely performed treatment, although the proportion of operated patients is clearly lower in the older group in all series. ${ }^{2,8}$ Standard conservative treatment has been carried out in few cases, with percentages as low as $0 \%$ in one series. ${ }^{25}$ 


\begin{tabular}{l}
$\begin{array}{l}\text { Life-expectancy of older } \\
\text { women }\end{array}$ \\
\hline - age 65 , life expectancy 18.8 years \\
- age 75, life expectancy 11.9 years \\
age 85, life expectancy 6.6 years \\
\hline
\end{tabular}

Box 2
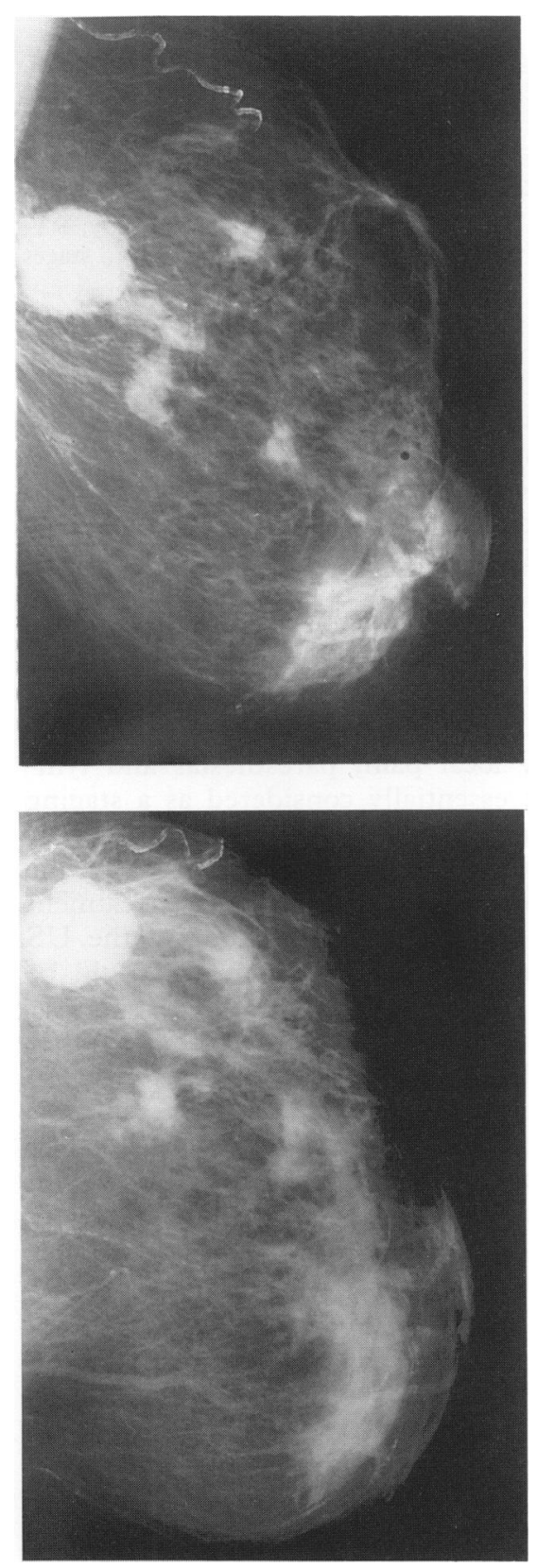

Figure Craniocaudal and lateral mammograms of left breast in an old woman $(88$ years): several nodular images (the greatest measuring $2.5 \mathrm{~cm}$ ) with malignant characteristics are seen, suggesting a multifocal carcinoma. Notice the low density of breast tissue in older patients, which allows a good contrast of tumoral lesions.
- Older patients receive a higher proportion of local excisions: $38 \%$ for women over 75 vs $2.6 \%$ for younger patients in one study. ${ }^{8}$ Axillary clearance is performed with variable frequency, ranging from $49 \%{ }^{23}$ to $90.8 \%{ }^{26}$

- Radiotherapy for any use (first treatment, adjuvant setting) has been less employed in the elderly: $65 \%$ of patients under 75 years received radiotherapy compared with only $33 \%$ of older patients. ${ }^{8}$ Implant Ir techniques are seldom used, as this can imply a general anaesthesia. ${ }^{31}$

- Hormonotherapy has often been used as the only treatment among elderly patients with stage II breast cancer, but not in younger women with similar extent of the disease. ${ }^{8}$

- Chemotherapy has rarely been employed in aging patients, even in most recent reports, with percentages ranging from $3 \%{ }^{27}$ to $9 \%{ }^{26}$

- Combined treatment modalities are not likely to be indicated in elderly patients: surgery and less often radiotherapy were used as the only therapy in the years prior to tamoxifen. Since then, surgery, surgery plus hormonotherapy or hormonotherapy alone have been the most frequently used strategies.

When can recurrence be expected? What are the prognostic factors affecting disease-free survival in elderly breast cancer patients?

Recurrent disease usually occurs between the second and third year after first treatment (mostly surgery and/or tamoxifen for operable disease, see table 1). ${ }^{21,26,28,32-34}$ In the recent series of Gazetas, ${ }^{31}$ which included $83.3 \%$ of early-stage patients, and with a widely applied adjuvant treatment, the average time to recurrence was 27.7 months. According to this, short- or median-term control of the disease cannot be guaranteed, even for early disease and when life-expectancy is believed to be short because of comorbid conditions.

Clinical tumour size,${ }^{27}$ ganglionar involvement, ${ }^{26}$ clinical TNM stage ${ }^{27}$ and grade of tumour $r^{35,36}$ have been shown to influence local disease-free survival. ${ }^{27}$ In some studies ${ }^{28,37}$ 'suboptimal therapy' (local excision or lumpectomy without complementary irradiation, no ganglionar treatment) has correlated with a higher proportion of local and regional recurrence, although in most cases it has not had a negative effect on survival. ${ }^{8,26,27}$

Survival in elderly breast cancer patients. Are there any differences compared with younger patients?

Overall survival in elderly cancer patients at five years ranges from $30 \%{ }^{21,24}$ to $50 \%{ }^{27}$ (box 3 ). In elderly populations, an accurate survival analysis must take into account the expected survival of the general population (relative survival) or the number of deaths due to any cause other than breast cancer (disease-specific survival, DSS). Most authors ${ }^{2,22,38}$ have reported five-year relative survival for elderly breast cancer patients to be slightly worse than for younger patients. Bergman et $a l,{ }^{8}$ however, only found lower relative survival rate for the elderly at 10 years $(<75: 57 \%,>75: 32 \%)$ and this difference disappeared after controlling for stage.

Similarly, a trend towards a worse disease-specific survival rate in older patients has been shown in several studies. ${ }^{24,25}$ Bergman $^{24}$, however, found a 7 -year DSS of $55 \%, 65 \%$, and $50 \%$ for women aged 55-64, 65-74, and over 75 years, respectively, so that a categorically worse DSS for the elderly could not be demonstrated.

Among the elderly, a noticeable proportion of deaths occur from causes other than neoplastic disease (from $11.6 \%{ }^{26}$ to $54.8 \%{ }^{21}$ ). In spite of this, the impact of breast cancer on survival should not be underestimated. Davis reported a median survival of 20 months for patients who died from the disease, which was clearly lower than the 40 months observed among non-cancer deaths. ${ }^{21}$

Advanced stage $e^{8,19,21,22}$ and nodal involvement ${ }^{8}$ negatively influence survival. The hormonal status has shown statistical significance in survival only for node-negative patients, for whom the risk of dying from breast cancer seems to be 8.4 -fold higher than in oestrogen-receptor-positive groups. In most ${ }^{8,26,27}$, but not all ${ }^{28}$ studies, suboptimal therapy applied to elderly patients did not modify survival.

\section{Treatment of breast cancer in the elderly}

EARLY-STAGE DISEASE

Nowadays, ${ }^{39}$ partial mastectomy with axillary dissection plus postoperative breast irradiation is the preferred treatment for patients with early disease; total mastectomy should be reserved for multicentric tumours or when cosmetic results of partial mastectomy are likely to be poor. 
Table 1 Time to treatment failure after first therapy (mainly operable disease) in elderly breast cancer patients

\begin{tabular}{|c|c|c|c|c|c|c|c|}
\hline $\operatorname{Ref}$ & $n$ & Age (years) & $\begin{array}{l}\text { Early stage } \\
\left(\begin{array}{c}o \\
o\end{array}\right)\end{array}$ & $\begin{array}{l}\text { Treatment mainly performed } \\
\left(\begin{array}{c}0 \\
0\end{array}\right)\end{array}$ & $\begin{array}{l}\text { Recurrences } \\
L / D \\
\left(o_{0}\right)\end{array}$ & $\begin{array}{l}\text { Median time } \\
\text { to failure } \\
\text { from surgery } \\
\text { (months) }\end{array}$ & $\begin{array}{l}\text { Mean } \\
\text { follow-up } \\
\text { (months) }\end{array}$ \\
\hline 21 & 198 & $83(80-94)$ & 58.6 & $\begin{array}{l}\text { mastectomy: } 74.8 \\
\text { adj RT: } 23.2\end{array}$ & 21.7 & $\begin{array}{l}58 \% \text { recurrences } \\
\text { before } 36\end{array}$ & NS \\
\hline 26 & 479 & $76(70-95)$ & 83.3 & $\begin{array}{l}\text { mastectomy: } 78.2 \\
\text { adj HT/CT (node +): } 73.9\end{array}$ & 21.3 & 27.7 & 55 \\
\hline 28 & 150 & $84(80-95)$ & 71 & mastectomy: $69^{\star}$ & $6 \star \star$ & 37.4 & 68 \\
\hline 32 & 96 & 76 & 84 & $\begin{array}{l}\text { wide local excision (all cases) } \\
\text { (no adj treatment) }\end{array}$ & 35 & 31 & 47 \\
\hline 33 & 109 & $79(70-92)$ & 89 & $\begin{array}{l}\text { wide lumpectomy } \\
\text { adj TMX: } 80.4 \\
\text { adj RT: } 16\end{array}$ & $9.1 / 6.5$ & $33(\mathrm{~L}) / 25(\mathrm{D})$ & 44 \\
\hline 34 & 40 & $82(68-93)$ & 83 & TMX & 27.2 & 33 & 29 \\
\hline
\end{tabular}

L: recurrence loco-regional; D: distant metastases (L + D if non-specified); adj: adjuvant; HT: hormonotherapy; CT: chemotherapy; RT: radiotherapy; TMX: tamoxifen; NS: not specified. ${ }^{\star}$ Mastectomy was performed in $85 \%$ of I-II staged-patients. $\star \star$ Referred only to stages I-II (clearly operable patients).

\begin{tabular}{|l|}
\hline $\begin{array}{l}\text { Survival of elderly breast } \\
\text { cancer patients }\end{array}$ \\
\hline - $30-50^{\circ}{ }_{0}$ of overall survival at 5 \\
years \\
- trend to worse relative and \\
disease-specific survival than \\
younger patients \\
- $12-55^{\circ}$ of 'non-cancer deaths' \\
double median survival for older \\
breast cancer patients who died \\
from non-malignant causes \\
\hline
\end{tabular}

Box 3

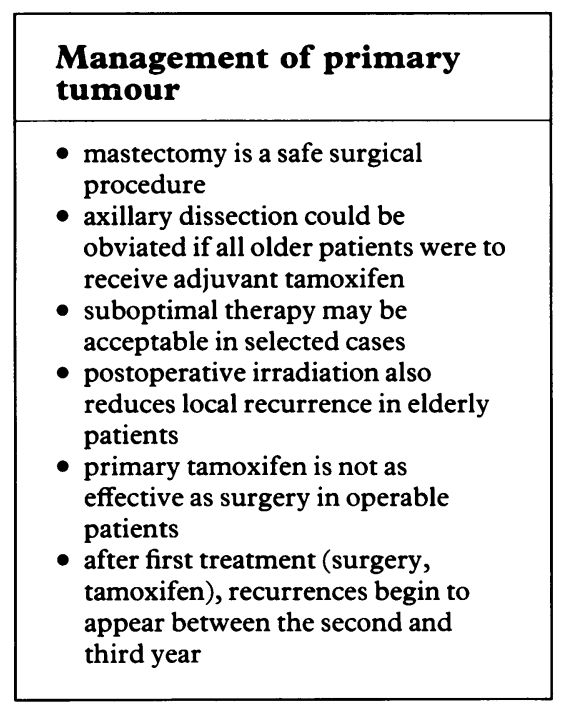

\section{Box 4}

These recommendations are based on three large randomised trials ${ }^{40-42}$ that compared total mastectomy with breast-conserving surgery plus postoperative irradiation. No differences in disease-free survival or overall survival were found between treatment groups in any of these three trials. Unfortunately, the conclusions of these trials are not easily applied to elderly patients due to the low number of women over 65 years included.

Surgery

Mastectomy has proven to be a safe surgical procedure in older patients, with mortality $(0-5 \%)$ and morbidity $(13-25 \%)$ rates similar to those reported for younger patients. ${ }^{27-30}$

Axillary clearance can be followed by local pain, paresthesias and lymphedema. Ganglionar dissection must be essentially considered as a staging rather than a therapeutic procedure. It becomes crucial when the decision to deliver adjuvant treatment is based on pathological node involvement. On the contrary, if all postmenopausal women were to receive complementary treatment with tamoxifen, in accordance with the latest recommendations of the US National Insitutes of Health ${ }^{39}$ the axillary clearance performance could be obviated.

As breast-conserving treatment and mastectomy show a similar efficacy, other factors, such as quality-of-life and perception of body image, must be taken into consideration. According to on $\mathrm{e}^{43}$ of the few studies specifically addressing the issue in the elderly, familial support was more relevant in the quality-of-life than the surgical procedure chosen. 'Wide local excisions' in a short-admission regimen $^{32,33}$ or under local anaesthesia ${ }^{44}$ have been reported as an alternative treatment for older breast cancer patients, even for those with clinical positive nodes. ${ }^{32}$ Adjuvant treatment (tamoxifen, radiotherapy) was added in few cases. ${ }^{33}$ After an average follow-up of 45 months, recurrence rates ranged from $9.1 \%$ to $35 \%{ }^{32}$ These alternative procedures may be an acceptable first treatment for patients reluctant to spend a long stay in the hospital, ${ }^{33}$ unfit to undergo major surgery ${ }^{44}$ or with difficulties in complying with radiotherapy protocols. ${ }^{32}$ Otherwise, standard therapy is preferable.

\section{Radiotherapy}

Postoperative irradiation is a well-tolerated procedure in any age group. . $8,30,45^{2}$ Among women under 70 years, there is currently strong evidence for the efficacy of postoperative irradiation in reducing local recurrence, without affecting survival ${ }^{42,45,46}$ As for elderly women, less local recurrence with aging in the absence of postoperative radiotherapy has been noted, ${ }^{45,47,48}$ with rates as low as $3 \%$ in one series. ${ }^{47}$ The results led some authors to suggest that this procedure could be reasonably obviated in this group of patients, for whom daily transfer to a radiotherapeutic centre might imply an additional burden. Nevertheless, an undoubted benefit in terms of local recurrence-free survival $\left(39.1{ }^{\circ}{ }_{0} v s 4^{\circ}{ }_{0}\right)$ and breast preservation $(54 \%$ vs $12 \%$ ) for women over 60 receiving postoperative irradiation has been observed..$^{45}$

Primary tamoxifen

Tamoxifen has been widely investigated as first treatment in elderly patients with operable disease. According to criteria developed by the International Union 


\begin{tabular}{l} 
Adjuvant therapy \\
\hline complementary treatment with \\
tamoxifen reduces local regional \\
failures and, when given for a long \\
period, positively influences \\
survival \\
- at present, adjuvant chemotherapy \\
cannot be considered as standard \\
therapy, even in node-positive \\
patients \\
\hline
\end{tabular}

Box 5
Against Cancer, an average of $60 \%$ of positive overall responses has been noted, with an additional $20 \%$ of 'stable disease'. ${ }^{49-54}$ Despite these response rates, an increasing percentage of relapse is found during longer follow-up, requiring additional local treatment. In the retrospective series with longest follow-up, ${ }^{55}$ the disease was not controlled by tamoxifen to the time of death or most recent follow-up in $62 \%$ of patients.

Three randomised studies have compared surgery $v$ s tamoxifen as initial therapy in early disease $e^{35,36,56-58}$ (see table 2). Local progression or relapse was more frequent in the tamoxifen group in the three trials. The difference reached statistical significance in two of them, including the study with the longest follow-up. ${ }^{36}$ No differences with regard to overall survival ${ }^{35,36,57,58}$ or quality of life were detected. Nevertheless, recent up-dated data from one of these series ${ }^{58}$ have also disclosed a marginal benefit on survival for the surgically treated group. In the light of these data, tamoxifen cannot currently be considered an equally effective alternative to surgery for elderly patients with operable breast cancer.

\section{Adjuvant tamoxifen (hormonotherapy)}

The benefit of adjuvant tamoxifen in older women has been demonstrated by a worldwide meta-analysis ${ }^{59}$ and by at least four randomised trials ${ }^{60-63}$ specifically carried out in older patients. According to these data adjuvant tamoxifen, given for one year or until progression, was useful in significantly reducing the number of local regional recurrences and contralateral breast cancer and in extending the time to treatment failure, ${ }^{61,62}$ although it did not modify survival. The benefit was evident even for patients whose oestrogen receptors were negative ${ }^{61}$ or unknown. ${ }^{62}$ Adjuvant tamoxifen for five years after mastectomy positively influenced survival when compared to the drug given at first recurrence. The benefit was only evident after three years of randomisation. ${ }^{63}$

An increased rate of cardiovascular deaths was found in one trial ${ }^{61}$ among patients receiving the drug. This finding has not been reported in the other studies. On the contrary, due to its partial oestrogenic properties, tamoxifen has proven useful in preventing osteoporosis, reducing levels of low-density cholesterol, and even decreasing the risk of myocardial infarction when given over a long period. ${ }^{64}$ Therefore, 'non-cancer arguments' favouring tamoxifen's use in the elderly can be made.

\section{Adjuvant chemotherapy}

In a recent meta-analysis, ${ }^{65}$ the use of adjuvant chemotherapy in women aged 60-69 years implied a significant reduction of recurrences, although the mortality rate was only $10 \%$ lower. Chemotherapy in the adjuvant setting did not seem to be beneficial in the 366 women over 70 included in the meta-analysis.

As for individual trials addressing the question, nearly all have been centred on positive node patients aged 50-70 years. Most of these studies have found that complementary chemotherapy is useful at increasing disease-free survival, but has no clear effect on overall survival. The trials using cyclophosphamide/ methotrexate/5-fluorouracil (CMF)-based regimens ${ }^{66-68}$ have failed to demonstrate a benefit in overall survival, while two studies ${ }^{69,70}$ using doxorubicincontaining regimens, found a reduction in mortality ranging from $38 \%{ }^{69}$ to $45 \%{ }^{70}$

In conclusion, adjuvant chemotherapy cannot be considered as standard treatment in node-positive women over 70 years old. It might be useful, however, in certain subsets of patients with aggressive disease.

Table 2 Randomised studies comparing surgery $(S)$ to tamoxifen $(T)$ as initial therapy in older patients with operable disease

\begin{tabular}{|c|c|c|c|c|c|c|c|c|}
\hline \multirow[b]{2}{*}{ Ref } & \multirow[b]{2}{*}{$n$} & \multirow[b]{2}{*}{ Age (years) } & \multirow[b]{2}{*}{ Comparison } & \multirow{2}{*}{$\begin{array}{l}\text { Median } \\
\text { follow-up } \\
\text { (months) }\end{array}$} & \multicolumn{3}{|c|}{ Outcome $(T / S)$} & \multirow[b]{2}{*}{ Comments } \\
\hline & & & & & $L R$ & $D$ & OS & \\
\hline 56 & 116 & $75(70-95)$ & $\mathrm{T} v \mathrm{~s}^{\star} \mathrm{S}^{\star}$ & - & $\begin{array}{l}25 / 38 \\
\text { NS }\end{array}$ & $\begin{array}{l}13 / 18 \\
\text { NS }\end{array}$ & $\begin{array}{l}63 / 65 \\
\text { NS }\end{array}$ & $\begin{array}{l}\text { Included } 20 \% \mathrm{~T}_{3}-\mathrm{T}_{4} \text { in } \mathrm{T} \text {-arm, } \\
36 \% \mathrm{~T}_{3}-\mathrm{T}_{4} \text { in } \mathrm{S} \text {-arm } \\
\text { Excess of recurrences in surgical } \\
\text { group }\end{array}$ \\
\hline 36 & 135 & $75(70-88)$ & $\mathrm{T}$ vs $\mathrm{S}^{\star \star}$ & 65 & $\begin{array}{l}46 / 20 \\
\mathrm{p}<0.0001\end{array}$ & $\begin{array}{l}24 / 34 \\
\text { NS }\end{array}$ & $\begin{array}{l}63 / 59 \\
\text { NS }\end{array}$ & $\begin{array}{l}\text { Included only } T \leqslant 5 \mathrm{~cm} \\
\text { Longest follow-up }\end{array}$ \\
\hline 58 & 434 & $>70$ & $\begin{array}{l}T v s \\
T+S \dagger\end{array}$ & 42 & $\begin{array}{l}45 / 21 \dagger \dagger \\
\mathrm{p}<0.0001\end{array}$ & & $\begin{array}{l}29 / 21 \\
\mathrm{p}=0.048\end{array}$ & $\begin{array}{l}\text { No differences in quality-of-life or } \\
\text { distant metastases in preliminary } \\
\text { report }^{57}\end{array}$ \\
\hline
\end{tabular}

T: tamoxifen; S: surgery; NS: non-statistical significance; LR: locoregional failure; D: distant failure; OS: overall survival. ${ }^{\star}$ Mastectomy/ lumpectomy; ${ }^{\star}$ wedge mastectomy \pm axillary clearance; $\nmid$ most adequate surgery according to surgeon; $\dagger \dagger$ locoregional failure measured by need to change treatment. 


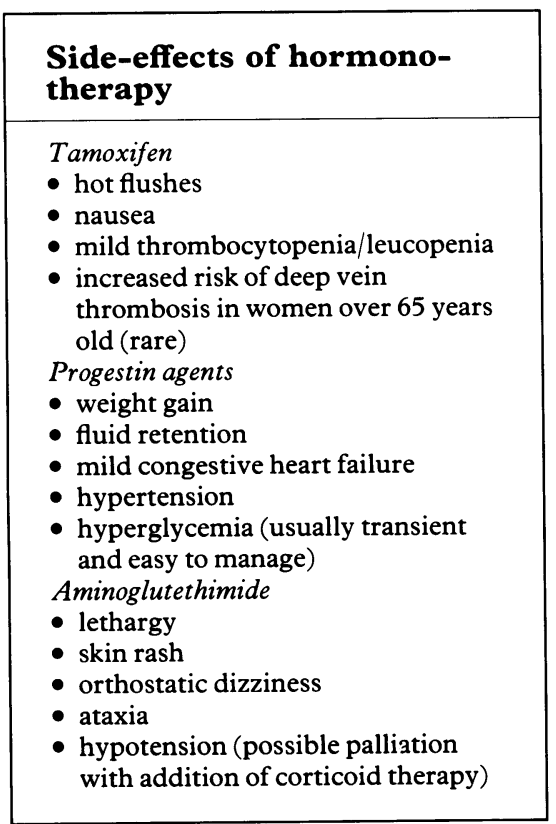

Box 6
ADVANCED DISEASE: PALLIATIVE SYSTEMIC TREATMENT

The realistic goal of treatment for women with recurrent or overt distant disease is palliation of symptoms and secondly, improvement of survival. With this concept in mind, efficacy, and particularly toxicity of the different treatments, hormonotherapy or chemotherapy, must always be accurately assessed.

\section{Hormonotherapy}

The percentage of breast tumours sensitive to hormonal treatment increases with advancing age. The anti-oestrogen tamoxifen is the drug of choice, as it is also the best tolerated. Hot flushes are the most common adverse effect. ${ }^{71,72}$ Tamoxifen can induce a remission rate of $30-40 \%$ in advanced disease when used in previously untreated patients, ${ }^{73}$ with a median duration of response of 1 to 2 years.

Progestional agents such as megestrol acetate or medroxyprogesterone acetate, and aromatase inhibitors such as aminoglutethimide ${ }^{74,75}$ have proven to be nearly as effective as tamoxifen in terms of response, but with somewhat more toxic effects, which can be particularly relevant in older patients. They should be regarded as second or third-line drugs.

\section{Chemotherapy}

Commonly used chemotherapy regimens include cyclophosphamide, methotrexate, 5-fluoruracil and doxorubicin. Before starting a cytotoxic regimen in an elderly patient, any organ dysfunction that may increase toxicity must be ruled out. The use of methotrexate, either as monotherapy or in combination, demands correct renal function, which is often impaired in advanced age. Concomitant treatment with non-steroidal anti-inflammatory drugs (frequently prescribed in geriatric populations) must be avoided, because of their negative effect on methotrexate renal plasma clearance. Cardiac function must be monitored before giving a doxorubicin-containing schedule. Cardiac toxicity of doxorubicin is dose- and age-dependent. On the other hand, the drug is considered the most active single agent for breast carcinoma. Therefore, among elderly patients with increased risk for congestive heart failure, alternative schedules such as lower doses of doxorubicin once weekly, or the use of related and also active drugs (4-epirubicicin, idarubicin, mitoxantrone) with less cardiotoxicity, must be considered. Mitoxantrone appears to be a particularly suitable drug in elderly patients, since it causes less cardiac toxicity, less nausea and vomiting, and less alopecia.

There is little experience about combination chemotherapy regimens in elderly breast cancer patients, especially in those over 70 years. Begg et a $l^{6}$ reported that the frequency of severe toxicity in terms of sepsis, bleeding, vomiting or neurological or cardiac dysfunction, was the same in women under 60 years and in those aged 60 to 65 . Only a minor increase in haematological toxicity was seen in the older group.

In spite of these results, initial dosage of classical schedules continues to be a matter for debate. Gelman and Taylor ${ }^{77}$ recommended a CMF dosage based on creatinine clearance to neutralise potential increments in toxicity of cyclophosphamide and methotrexate in elderly patients. Beex ${ }^{78}$ suggested that, among the elderly, and because of the haematological toxicity, the median doses of CMF administered during the first three cycles can rarely overcome the $75 \%$ of classical doses. Christman et $a l^{9}$ found similar non-haematological toxicity in women over 70 receiving total doses of doxorubicin-containing schedules as $\widetilde{N}$ compared to their counterparts treated with an intended dose of $75 \%$. Haematological toxic effects were also similar within age groups, but the elderly had twice the frequency of life-threatening neutropenia and the only drugrelated septic deaths. These authors recommended caution in extrapolating these results, as the otherwise healthy population studied, might not be representative of all older patients. Based on data published elsewhere, ${ }^{80}$ reporting the same degree of benefit for both elder and younger patients with erythropoietin or GM-CSF treatment, the authors also suggested the possibility of diminishing neutropenia by using this kind of haematological support.

Effectiveness of chemotherapy in elderly patients was also discussed in Christman's work. ${ }^{79}$ In the multivariate analysis performed, age was not significantly associated with response to cytotoxic treatment. In Gelman's experience, ${ }^{77}$ doses of cyclophosphamide and methotrexate were adapted to renal $\frac{8}{0}$ function and the dose of 5 -fluorouracil was reduced. The authors found a $38 \%$ overall response, which was lower than the response rate observed in younger patients using classical CMF doses. 
Chemotherapy vs hormonotherapy

Chemotherapy is generally considered for patients with massive liver metastases, lymphangitic involvement of lung or skin, failure to third hormonal line or simply rapidly growing disease. Taylor $e t a^{81}$ compared tamoxifen to CMF as initial therapy for inoperable, recurrent or metastatic breast cancer disease in older women. A cross-over to the alternative treatment was performed at progression. Response rates were $45 \%$ and $38 \%$ on first-line treatment, and $29 \%$ and $31 \%$ upon cross-over to tamoxifen and CMF, respectively. Survival tended to favour tamoxifen as initial treatment, even among oestrogen-receptornegative patients, although this was not statistically significant. The authors reported that initiation with tamoxifen rather than CMF chemotherapy was justified in almost all situations.

\section{Future directions}

An increasing volume of affected patients on one hand, and poorly defined patterns of care on the other, make breast cancer in the elderly a major healthcare issue, demanding special social and health efforts and intensive clinical research. The investigation should be focused on defining the effectiveness of standard treatments in older women with breast cancer. In particular, four main areas need to be studied: the value of radiotherapy and axillary clearance after breast-conserving surgery, the optimal duration of adjuvant tamoxifen, the indications for adjuvant chemotherapy and, finally, the role of less aggressive therapies for patients with poor performance status.

1 Boring CC, Squires TS, Tong T. Cancer statistics, 1991. CA Cancer f Clin 1991; 41: 19-36. 2 Yancik R, Ries LG, Yates JW. Breast cancer in aging women. A population based study of contrasts in stage, surgery and survival. Cancer 1989; 63: 976-81.

3 Joensuu H, Toikkanen S. Comparison of breast carcinomas diagnosed in the $1980 \mathrm{~s}$ with those diagnosed in the 1940s to $1960 \mathrm{~s}$. BMF 1991; 303: 155-8.

4 Haynes SG, Feinleb M. Epidemiology of aging. Bethesda Md: DHHS Publ, 1980; pp 80-969.

5 Departament de Sanitat i Seguretat Social de Catalunya. La situació de la salut, dels seus condicionants $i$ dels serveis a Catalunya. Generalitat de Catalunya. Departament de Sanitat i Seguretat Social, Pla de salut de Catalunya 1993-1995, Barcelona, 1993; p 37.

6 Greenfield S, Blanco DM, Elashoff RM, Ganz PA. Patterns of care related to age of breast cancer patients. $\mathcal{F} A M A$ 1987; 255: 3385-90.

7 Goodwin JS, Hunt WC, Samet JM. Determinants of cancer therapy in elderly patients. Cancer 1993; 72: 594-601.

8 Bergman L, Kluck HM, Leeuwen van FE, et al. The influence of age on treatment choice and survival of elderly breast cancer patients in south-eastern Netherlands: a population-based south-eastern Netherlands: a population-b
study. Eur $\mathcal{F}$ Cancer 1992; 28A: 1475-80.

9 Study. Eur F Cancer 1992; 28A: 1475-80. V. Age as predictor of diagnostic and initial
V. treatment intensity in newly diagnosed breast cancer patients. F Gerontol Med Sci 1989; 44: 46-50.

10 Guralnik JM, La Croix AZ, Everett DF, Kovar MG. Aging in the eighties: the prevalence of comorbidity and its association with disability. In: Advanced data from vital and health statistics Hyattsville MD: National Center for Health Statistics, 1989; No 170.

11 Elston JM, Koch GG, Weissert WG. Regression-adjusted small area estimates of functional dependency in the noninstitutionalized American populations age 65 and over. Am f Public Health 1991; 81: 335-43.

12 Goodwin JS, Hunt WC, Samet JM. A population-based study of functional status and nocial support of elderly patients newly diag nosed with

13 US Bureau of the Census. Projections of the populations of the United States, by age, sex and race: 1983-2080. In: Current populations reports. Washington DC, US Govern Printing Office, 1984; series P-25, no 952.

14 Silvestrini R, Daidone MG, Di Fronzo G, Morabito A, Valagussa P, Bonnadona G. Prognostic implications of labeling index versus estrogen receptors and tumor size in nodenegative breast cancer. Breast Cancer Res Treat 1986; 7: 167-9.

15 Moran RE, Black MM, Alpert L, Straus MJ. Correlation of cell-cycle kinetics, hormone receptors, histopathology, and nodal status in human breast cancer. Cancer 1984; 54: 1586-90.
16 Elwood JM, Godolphin W. Oestrogen receptor in breast tumors: associations with age, menopausal status, and epidemiological and clinical features in 735 patients. $\mathrm{Br} \mathcal{f}$ Cancer 1980; 42: 635-44.

17 Parl FF, Wagner RK. The histopathologic evaluation of human breast cancers in correlation with estrogen receptor values. Cancer 1980; 46: $362-7$

18 Valentini B, Silvestrini R, Daidone MG, et al. 3H-Thymidine labeling index, hormone receptors, and ploidy in breast cancers from elderly tors, and ploidy in breast cancers from elderly patients.

19 Mueller CB, Ames F, Anderson GD. Breast cancer in 3358 women: age as a significant determinant in the rate of dying and causes of death. Surgery 1978; 83: 123-32.

20 Hunt KE, Fry DE, Bland KI. Breast carcinoma in the elderly patient: an assessment of operative risk, morbidity and mortality. Am 7 Surg 1980; 140: 339-42.

21 Davis SJ, Karrer FW, Moor BJ, Rose SG, Eakings G. Characteristics of breast cancer in women over 80 years of age. Am $\exists$ Surg 1985; 150: $655-8$.

22 Adami HO, Malker B, Holmberg L, Persson I, Stone $B$. The relation between survival and age at diagnosis of breast cancer. N Engl f Med 1986; 315: 559-63.

23 Yancik R, Ries LG. Caring for elderly cancer patients. Quality assurance considerations. Cancer 1989; (suppl) 335-41.

24 Bergman L, Dekker G, Leeuwen van FE, Huisman SJ, Dam van FSAM, Dongen van JA. The effect of age on treatment choice and survival in elderly breast cancer patients. Cancer 1991; 67; 2227-34.

25 Bergman L, Dekker G, Kerkhoff van EHM, Peterse HL, Dongen van JA, Leeuwen van FE. The influence of age and comorbidity on treatment choice and its effect on survival in elderly ment choice and its effect on survival in elderly patients with breast can
Treat 1991; 18: 189-98.

26 Gazetas P, Estabrook A, O'Neil J, Sciacca R Importance of adequate staging and of hormone receptors in women older than age 70 with breast cancer. Ann Surg 1992; 216: 22-6.

27 Lacasta A, Aren O, Climent MA, et al. El cáncer de mama en mujeres mayores de 75 años. Clin Invest Ginecol Obstet 1994; 21: 8-17.

28 Swanson RS, Sawicka J, Wodd WC. Treatment of carcinoma of the breast in the older geriatric patient. Gynecol Obstet 1991; 173: 465-9.

29 Svastics E, Sulyok Z, Beszynyak I. Treatment of breast cancer in women older than 70 years. $f$ Surg Oncol 1989; 41: 19-21.

30 Amsterdam E, Birkenfeld S, Gilad A, Krispin $M$. Surgery for carcinoma of the breast in $M$. Surgery for carcinoma of the breast in
women over 70 years of age. $f$ Surg Oncol 1987; 35: $180-3$.

31 Henderson IC, Canellos GP. Cancer of the breast. $N$ Engl' f Med 1988; 302: 17-29.
32 Reed MWR, Morrison JM. Wide local excision as the sole primary treatment in elderly patien with carcinoma of the breast. Br $\mathcal{F}$ Surg $1989 ; 76$; 898-900.

33 Galante E, Cerrotta A, Martelli G, Del Prato I, Moglia D, Piromalli D. Treatment of breast cancer in elderly women: retrospective analysis of 111 wide lumpectomies performed in a day hospital regimen between 1982 and 1988 . Tumori 1992; 78: 111-4.

34 Foudraine NA, Verhoef LCG, Burghouts JTM Tamoxifen as sole therapy for primary breas cancer in the elderly patient. Eur $\mathcal{F}$ Cancer 1992 28A: 900-3.

35 Robertson JFR, Todd JH, Ellis IO, Elston CW, Blamey RW. Comparison of mastectomy with tamoxifen for treating elderly patients with operable breast cancer. BMF 1988; 297: 20-7.

36 Robertson JFR, Ellis IO, Elston CW, Blame RW. Mastectomy or tamoxifen as initial therapy for operable breast cancer in elderly patients: 5-year follow-up. Eur $\mathcal{f}$ Cancer 1992; 28A: 908-10.

37 Hayworths PJ, Henderson M, Bennet RC. Breast cancer, in the elderly: treatment Breast cancer in the elderly: treatment of
operable disease. Aust NZ $\mathcal{f}$ Surg 1992; 62: operable
$100-4$.

38 Host $\mathrm{H}$, Lund E. Age as prognostic factor in breast cancer. Cancer 1986; 57: 2217-21.

39 NIH consensus conference. Treatment of early stage breast cancer. $\mathscr{F} A M A$ 1991; 265: $391-5$.

40 Sarrazin D, Le M, Rouesse J, et al. Conservative treatment versus mastectomy in breast cancer tumors with macroscopic diameter of 20 millimeters or less. The experience of the Institut Gustave-Roussy. Cancer 1984; 53: 1209-13.

41 Veronesi U, Banfi A, Del Vecchio $M$, et al. Comparison of Halsted mastectomy with quadrantectomy, axillary dissection, and radiotherapy in early breast cancer: long-term results. Eur $¥$ Cancer Clin Oncol 1986; 22: 1085-9.

42 Fisher B, Redmond C, Poisson R, et al. Eightyear results of a randomized trial comparing year results of a randomized trial comparing total mastectomy and lumpectomy with or without irradiation in the treatment of

43 Garz PA, Schag CC, Polinsky ML. Rehabilitation needs and breast cancer: the first month after primary therapy. Breast Cancer Res Treat 1987; 10: 243-53.

44 Devereux DF. Successful treatment of stages IIIa and IIIb carcinomas of the breast mastectomy in the elderly high risk patient using local anesthesia. Surg Gynecol Obstet 1987; 165: $38-40$.

45 Kantorowitz DA, Poulter CA, Sischy B, et al. Treatment of breast cancer among elderly women with segmental mastectomy or segmental mastectomy plus postoperative radiotherapy. tal I Radiat Oncol Biol Phys 1988; 15: 263-70. 
46 Fisher B, Redmond C, Fisher ER, et al. Tenyear results of a randomized clinical trial comparing radical mastectomy and total mastectomy
with or without irradiation. $N$ Engl $f$ Med 1985; with or without

47 Nemoto T, Patel JK, Rosner D, Dao TL, Schuh $M$, Penetrante $R$. Factors affecting recurrence in lumpectomy without irradiation for breast cancer. Cancer 1991; 67: 2079-82.

48 Veronesi U, Luini A, Vecchio del M, et al. Radiotherapy after breast-preserving surgery in women with localized cancer of

49 Preece PE, Wood RAB, Mackie CR, Cushieri A. Tamoxifen as initial sole primary treatment in elderly patients with carcinoma of the breast. elderly patients with carcinc

50 Helleberg A, Lundgren B, Norin T, Sander S Treatment of early localised breast cancer in elderly patients by tamoxifen. Br $\mathcal{F}$ Radiol 1982 ; 55: $511-5$.

51 Bradbeer JW, Kyngdon J. Primary treatment of breast cancer in elderly women with tamoxifen. Clin Oncol 1983; 9: 31-4.

52 Allan SG, Rodger A, Smyth JF, Leonard RCF, Chetty U, Forrest APM. Tamoxifen as primary treatment of breast cancer in elderly or frail patients. $B M \mathcal{F}$ 1985; 290: 358 .

53 Falk GL, Gwynne-Jones D, Gray JG. Efficacy of tamoxifen as the primary treatment of operable breast cancer in the high risk patient. Aust NZ ₹ Surg 1989; 59: 543-5.

54 McDonald PJ, Carpenter R, Royle GT, Taylor I. Poor response of breast cancer to tamoxifen. Postgrad Med F 1990; 66: 1029-314.

55 Horobin JM, Preece PE, Dewar JA, Wood RAB, Cushieri A. Long-term follow-up of elderly patients with locoregional breast cancer treated with tamoxifen only. Br F Surg 1991; 78: 213-7.

56 Gazet JC, Ford HT, Bland JM, Markopoulos Ch, Coombes RC, Dixon RC. Prospective randomised trial of tamoxifen versus surgery in elderly patients with breast cancer. Lancet 1988 26; 679-81.

57 Bates T, Riley DL, Houghton J, Fallowfield L, Baum M. Breast cancer in the elderly woman: a Cancer Research Campaign trial comparing treatment with tamoxifen and optimal surgery with tamoxifen alone. Br $\mathcal{f}$ Surg 1991; 78: with tam 4 .

58 Bates T, Riley D, Houghton J, Baum M, for the Bates T, Riley D, Houghton J, Baum M, for the Cancer Research Campaign Breast

59 Early Breast Cancer Trialist's Collaborative Group. Systemic treatment of early breast cancer by hormonal, cytotoxic, or immun therapy: 133 randomised trials involving 31,000 recurrences and 24,000 deaths among 75,000 women. Part 1. Lancet 1992; 339: 1-15.
60 Mouridsen HT, Andersen AP, Brincker H, Mouridsen HT, Andersen AP, Brincker HW, Dombernowsky P, Rose C, Andersen KW. Adjuvant tamoxifen in postmenopausal highrisk breast cancer patients: present status of Danish Breast Cancer Cooperat

61 Castiglione M, Richard DG, Goldhirsch A Adjuvant systemic therapy for breast cancer the elderly: competing causes of mortality. $\mathcal{f}$ Clin Oncol 1990; 8: 519-26.

62 Cummings FJ, Gray R, Tormey DC, et al. Adjuvant tamoxifen versus placebo in elderly women with node-positive breast cancer: long term follow-up and causes of death. $7 \mathrm{Clin}$ Oncol 1993; 11: 29-35.

63 Breast Cancer Trails Committee: Adjuvant tamoxifen in the management of operable breast cancer: the Scottish trial. Report from the Breast cancer: the Scottish trial. Report from the Breast Trials Office, (MRC), Edinburgh. Lancet 1987; 2: $171-5$.

64 McDonald CC, Stewart HJ. Fatal myocardial infarction in the Scottish adjuvant tamoxifen trial. The Scottish Breast Cancer Committee. BMF 199; 303: 435-7.

65 Early Breast Cancer Trialist's Collaborative Group. Systemic treatment of early breast cancer by hormonal, cytotoxic, or immune therapy: 133 randomised trials involving 31,000 recurrences and 24,000 deaths among 75,000 women. Part 2. Lancet 1992; 339: 71-85.

66 Carbone PP. Breast cancer adjuvant therapy. Cancer 1990; 66: 1378-86.

67 Boccardo F, Rubagotti A, Bruzzi P, et al. Chemotherapy versus tamoxifen versus chemotherapy plus tamoxifen in node-positive, esttherapy plus tamoxifen in node-positive, estrogen receptor-positive breast cancer patients: results of a multicentric Italian study. Breast Cancer Adjuvant Chemo-Hormone Therapy Cooperative
$1310-20$

68 Rivkin SE, Green S, Metch B, et al. Adjuvant CMFVP versus melphalan for operable breast cancer with positive axillary nodes: 10-year results of a Southwest Oncology Group Study. $\mathcal{F}$ Clin Oncol 1989; 7: 1229-38.

69 Fisher B, Redmond C, Legault-Poisson S, et al. Postoperative chemotherapy and tamoxifen Postoperative chemotherapy and tamoxifen of positive-node breast cancer patients aged 50 years and older with tumors responsive to years and older with tumors responsive to Adjuvant Breast and Bowel Project B-16. F Clin Adjuvant Breast and Bo

70 Bonadonna G, Valagussa P, Moliterni M. Adjuvant and neoadjuvant studies in stage $I$ and II breast cancer. In: Salmon ED, ed Adjuvant therapy of cancer. Philadelphia: Saunders, 1990.
71 Love RR, Cameron L, Connell BL, Leventha H Symptoms associated with tamoxifen treatmen in postmenopausal women. Arch Intern Med in postmenopausal

72 Fisher B, Brown A, Wolmark N, et al. Prolong ing tamoxifen therapy for primary breast cancer Findings from the National Surgical Adjuvan Breast and Bowel Project clinical trial. Ann Intern Med 1987; 106: 649-54.

73 Forrest APM. Tamoxifen comes of age. $\mathrm{Br} f$ Surg 1989; 76: 325-6.

74 Santen RJ, Worgul TJ, Samozlik E, et al. A randomized trial comparing surgical adrenalectomy with aminoglutethimide plus hydrocortisone in women with advanced breast cancer. $N$ Engl f Med 1981; 305: 545-51.

75 Smith IE, Fitzharris BM, McKinna JA Aminoglutethimide in treatment of metastatic Aminoglutethimide in treatment of metastat

76 Begg CB, Cohen JL, Ellerton J. Are the elderly predisposed to toxicity from cancer chemopredisposed to toxicity from cancer chemotherapy? An investigation using data from the Eastern Cooperative Oncolog

77 Gelman RS, Taylor SG. Cyclophosphamide, methotrexate, and 5-fluoruracil chemotherapy in women more than 65 years old with advanced breast cancer. The elimination of age trends in toxicity by using doses based on creatinin clearance. $\mathcal{F}$ Clin Oncol 1984; 2: 1404-13.

78 Beex LVAM, Hermus ARMM, Pieters GFFM, van Hoesel QGCH, Nooy MA, Mignolet F. Dose intensity of chemotherapy with cyclophosphamide, methotrexate and 5-fluorouracil in the phamide, methotrexate and 5-fluorouracil in the Cancer 1992; 28: 686-90.

79 Christman K, Muss HB, Cas LD, Stanley V. Chemotherapy of metastatic breast cancer in the elderly. The Piedmont Oncology Association experience. $\mathcal{F} A M A$ 1992; 268: 57-62.

80 Shank W, Balducci L. Recombinant hematopoietic growth factors (rHGF) may protect olde patients from chemotherapy myelodepression. Proc Am Soc Clin Oncol 1991; 10: 326 (abstract)

81 Taylor SG, Gelman RS, Falkson G, Cumming FJ. Combination chemotherapy compared to tamoxifen as initial therapy for stage IV breast cancer in elderly women. Ann Intern Med 1986; 104: 455-61. 